\title{
Risks and Their Management in Ensuring the Economic Security of the Enterprise
}

\author{
Irina Kirishchieva ${ }^{1,}$, , Mikhail Skorev ${ }^{1}$, and Tatiana Grafova ${ }^{1,2}$ \\ ${ }^{1}$ Department of Economics, Accounting and Analysis, Rostov State Transport University, Rostov-on- \\ Don 344038, Russia \\ ${ }^{2}$ Rostov Branch of Russian Customs Academy, Rostov-on-Don, 344002, Russia
}

\begin{abstract}
In modern economic conditions, the activities of an enterprise are associated with an increased level of risks in all areas of activity, therefore, ensuring its economic security should be accompanied by the formation and implementation of a risk management system built into the enterprise management system. The analysis of the current regulatory legal acts in the field of enterprise risks is carried out, various definitions of the "risk" category as a multifaceted concept in regulatory legal documents, as well as in scientific works are presented. The necessity of forming a risk management system from the position of ensuring the economic security of an enterprise has been substantiated. The purpose, objectives, principles, main directions, basic provisions, sequence of actions in the cyclical process of risk management are disclosed. Considered are the positive aspects in the effective regulation of the enterprise, which are accompanied by the use of a risk management system in the environment of the enterprise to ensure its economic security.
\end{abstract}

\section{Introduction}

In modern economic conditions, the economic activity of enterprises is associated with an increase in the level of risk in all areas of activity, therefore, ensuring the economic security of any organization should be accompanied by the formation and implementation of a risk management system necessary to strengthen its position at all levels. To minimize potential and real threats to economic security in the process of financial and economic activities, it is necessary to change the system of strategic and operational management of the enterprise, to determine the forms and methods of ensuring economic security, selected taking into account the requirements of the risk management system. Such conditions increase the importance of measures and mechanisms of the corporate system for ensuring economic security, taking into account risk management technologies.

\footnotetext{
* Corresponding author: irina_raf@list.ru
} 


\section{Key landmarks}

It should be noted that the risk management system is currently acquiring special relevance, since each enterprise, as part of the development of an economic security management strategy, tries to minimize the level of negative impact of threats that can affect the uninterrupted operation of its operation and the final financial result. Therefore, standardization and normative regulation of the risk management system is becoming an important tool for increasing the economic security of enterprises, the results of whose activities depend on the economic security of the national economy as a whole, the need to ensure which is stated in the "Strategy for the economic security of the Russian Federation for the period until 2030" [1], where risks and threats in terms of economic security are presented, modern challenges are concretized, definitions are given to such basic concepts as economic security, threats and risks in the field of economic security. Thus, the risk in economic security is referred to as the ability to harm the national interests of Russia in the economic sphere when the threat to economic security is realized. This characteristic of risk in the field of economic security can be fully transformed into an understanding of risks at the level of an economic entity.

The Concept for the Development of the National System for Combating the Legalization (Laundering) of Criminally Obtained Incomes and Financing of Terrorism [2] discloses the basic concepts of risk in this area and in this document the risk is interpreted as the possibility of causing damage to the national interests of Russia through illegal financial transactions. which are implemented by threats to national security and (or) in the process of which the vulnerability of the national system arises. In the Law "On the organization of insurance business in the Russian Federation" [3] it is noted that the insurance risk is a possible event, upon the occurrence of which insurance is carried out. The Federal Law "On Financial Lease (Leasing)" [4] discloses issues of insurance of entrepreneurial (financial) risks.

If earlier the regulation of risks at the enterprise was carried out at the level of technical regulation in accordance with the Federal Law "On Technical Regulation" [5], where the risk is interpreted in relation to the safety of products, production processes associated with it, in relation to operation, storage, transportation, sale, disposal and is associated with harm to the life, health of citizens, property of individuals, legal entities, state or municipal property, the environment, as well as life, health of animals and plants, then at the present time it is assumed that there is a risk management system at the enterprise in the form of providing a system internal control to reduce the likelihood of a negative impact of external and internal threats that negatively affect its key performance indicators.

The order of the Federal Tax Service of Russia "On Approval of the Requirements for the Organization of the Internal Control System" [6] defines the requirements for the formation of an enterprise risk management system. It reflects that the enterprise risk management system should be developed with the aim of organizing and functioning of the enterprise's internal control system. It should be aimed at:

- with timely prevention and minimization of negative consequences in which the enterprise does not achieve the goals of the effective implementation of its financial and economic activities;

- functioning on an ongoing basis and compliance with goals, objectives and strategy of the enterprises;

- regulation by organizational and administrative documents of the enterprise;

- ensuring the implementation of certain actions aimed at preventing or reducing the possible damage by exposure to I on the causes and consequences of risks;

- identification and assessment of risks on the basis of a comprehensive analysis and diagnosis of the consequences of all external and internal factors, as well as the conditions of the financial and economic activities of the enterprise. 
- creating conditions for the detection and analysis of existing or possible occurrence of new circumstances, can claim zit DATA ie, finding the camping in the financial, tax and other statements, as a result of which may be incorrectly calculated or not paid the tax and collection $\mathrm{s}$, insurance $\mathrm{f}$ fee 's, untimely submitted a and 1 , and generally not represented STATEMENTS s tax authority.

After analysing the current regulatory 's and legal acts in the sphere of enterprise risks, it can be argued that in the modern Russian state created a reliable normative o- legal framework to ensure the economic security of the state. However, it should be noted that the growth of various internal and external risks associated with the new political, legal and economic reality cannot but affect the provision of economic security, which predetermines an increase in the status of the enterprise risk management system.

Questions related to the study of the category of "risk" are considered in many modern scientific studies. Let's designate some of them. The versatility of the concept of "risk" is shown in the article Panfilova EA, which is an analysis of the basic concepts in relation to the risk presented its different definition to the conclusion th that the above phenomenon is multidimensional, quite ambiguous and its characteristics are determined by, in any aspect of it is considered [7] . So, Razuvaev V.V. gives a fairly extensive analysis of the concept of risk from the standpoint of different authors and approaches and concludes that, in general, risk is , first of all, characterized as an uncountable possibility of losses arising from uncertainty and which arises against the background of the possibility of winning" [8]. In the scientific work of Kuvshinkina E.B. notes that the risk is accepted to name some risk of the emergence of unexpected losses in the expected profit due to accidental and altered iyami in terms of economic activity [9]. V.I. Avdiyskiy describes the risk as potentially th possibility of occurrence of a controlled event, which occurs in an environment with the conditions of uncertainty in the process of realization of economic activities, Kotor th can be assessed in quantitative and qualitative position [10]. The study of various concepts of understanding risk is also present in the works of a large number of other authors, but in general, risk presupposes the presence of uncertainty and possible losses. However, considering the influence of risk as a negative factor for the management of the enterprise when making certain management decisions, one should take into account the fact that the risk for the enterprise can carry not only a negative, but a positive outcome, which depends on a competent decision made by the head of the enterprise, on the clarity of his actions.

\section{Formation of a risk management system}

In this regard, in a modern first period of development of the economy highlights the issue of creating within each company's own risk management system that is able to protect him from the influence of various negative factors, a timely warning of the possibility of threats. The formation of the risk management system at the enterprise is aimed at neutralizing and minimizing the likelihood of risks in the form of third-party factors or unfavourable business operations in order to efficiently use capital, reduce losses and maximize income.

Building a risk management system is one of the priority tasks to ensure the economic security of the organization and the successful development of the business. When creating a risk management system at an enterprise, it is necessary to develop mechanisms aimed at: - development of a competent organizational structure, which would be consistent with its strategic $m$ objectives and of the plans;

- maximum effective use of all resources of the enterprise in order to prevent possible emergence of threats, to ensure its stable operation both in the current period and in the future; - development of measures of social, legal, economic and organizational nature, which will be aimed at protecting the main areas of activity that are important for the existence and effective functioning of the enterprise when exposed to external and internal threats; 
- achievement of such a state of business processes, which ensures financial stability, balance, profitability of financial results, fulfilment of specified plans and goals, smooth operation and development of strategies for further development;

- development of protective mechanisms to ensure a direct impact on the potential of the enterprise (personnel, scientific and technical, production, etc.) of active or passive economic risks.

It should be noted that when creating a risk management system at an enterprise, management needs to monitor the main functional components of this system, which include various areas of its activities, namely: personnel policy, production activities, social protection, information flows, technological processes, etc. To do this, an enterprise needs to rely on a regulatory and legal framework, the application of which, in conjunction with legislative acts and internal corporate standards, will minimize the level of risk impact and ensure the efficient and safe functioning of financial and economic activities and, as a result, the achievement of economic security .

A modern risk management system is an integral part of the company's internal accounting system, which allows the company's management to achieve its goals and follow the chosen strategy with a minimum level of influence from third-party threats. The risk management system should be submitted to a set of the selected the leadership of the enterprise methods, procedures, guidelines, required to achieve the most efficient performance and the ability to adapt in a timely manner under the influence of changing external and internal factors. This is a multi-stage process of implementing procedures for identifying and assessing existing possible risks, aimed at setting strategic objectives for their elimination.

The main goals of risk management are to ensure economic security on the part of management and functional leaders, regardless of the type of organization and the type of its activities. With the goals set, the enterprise forms the tasks of risk management:

- collection, processing and analysis of information obtained from the external and internal environment, which can become a threat to the enterprise;

- formation and classification of risk factors and threats;

- identification of the degree of risk of the formed factors;

- development of a strategy for managing risk factors;

- formation of methods and tools to protect against threats;

- risk insurance;

- drawing up of special reporting forms on the formation of the factors of risk, evaluation is, and analysis.

An important point in the process of formation, implementation and application of the risk management system at the enterprise is the implementation of the principles on which it is built. These principles must be respected and followed by all those who form the risk management system and are responsible for its implementation. When building and implementing a risk management system, the following principles must be observed:

- goal orientation - setting goals, specifying them in the development strategy of the risk management system and all internal documents involved in this process;

- balance - the balance of risks and profits, ensuring this ratio on the basis of legal regulation, both legislative and intra-company;

- uncertainty - decision making taking into account the emergence of the risk of uncertainty\$ - consistency - aimed at a quick and timely response to emerging risks and threats, their identification and evaluation of possible restrictions I have its negative impact, reducing the level of possible losses;

- efficiency is based on the provision of timely, high-quality and reliable information, as well as on the use of methods of analysis and modelling of the development of situations that have 
arisen, on the basis of which the management makes effective management decisions in order to minimize the influence of negative factors;

- responsibility - empowering a manager or other official responsible for the timely implementation of high-quality measures to reduce the impact of risks on an economic entity; - efficiency - the effectiveness of the risk management system should be aimed at effectively ensuring the economic security of the company, obtaining economically justified and documented results of its activities;

- continuity - the entire system must constantly function and comply with the processes of regular implementation of the developed measures aimed at reducing the impact of risk processes;

- integration - decisions are made and approved taking into account the circumstances and the likelihood of negative consequences;

- extended impact - maximum provision of identification and resolution of emerging risk situations in all business processes of the enterprise.

The main key points in the formation of a risk management system are:

- embedding of the risk management system into the enterprise management system;

- determination of the list of strategic and tactical actions aimed at risk management, taking into account the distribution of strategies for the development of the structure of the enterprise;

- ensuring the compliance of the assigned tasks of the enterprise with the risk management system;

- the need to provide a feedback mechanism for adapting risk management methods and tools; - the relationship of tactical actions in the field of risk management and strategic planning with changes in the external and internal environment of the enterprise;

- formation and development of an organizational culture in the field of risk management.

Considering the risk management system as monitoring the efficiency and effectiveness of the enterprise, one should dwell on the main areas that it should include, namely:

- control over the implementation of the tasks set by the management and the management decisions taken on their basis;

- creation of a systematic process for monitoring and correcting risk situations and adverse events;

- monitoring the phenomena and risk factors;

- ensuring quality and the information transmitted between the units of the probability of occurrence of risk situations and threats.

Minimization of losses and the elimination of risks for the management of the organization is based on risk control, to about tory provides information support to the company's management when making management decisions. At the same time, control actions should be focused primarily on high-risk areas. Strict control must be carried out in relation to information about the risk, such as: composition, risk assessment, planning, analysis and others.

At the enterprise it is necessary to develop instructions, regulations, regulations for employees, which describe actions to identify risks and the operation of the enterprise in conditions of risky situations. The reporting on internal control should reflect the focus of risks, the strength of their impact on the activities of the enterprise. The values obtained during the risk control process help determine the level of their elimination and minimization.

Minimizing the aggregate risk is a cyclical process aimed at increasing the economic security of an enterprise. The cyclical process to minimize risks involves the following sequence of actions:

- identification of risk problems;

- assessment of the main areas of risks;

- measuring the likelihood of risk and its impacts; 
- risk ranking;

- establishing the desired results;

- development of options;

- choice of strategy;

- implementation of the strategy;

- monitoring, evaluation and, adjustment.

The presented stages allow us to conclude that minimizing and eliminating risks is the basis for the survival and development of a business. However, not all of the above steps can be used by the enterprise management. Depending on the goal and the available funds at the disposal of the enterprise, managers can independently make their choice and on how correctly the assessment of the sensitivity of the level of economic security to the consequences of risk reduction is determined, we can talk about the achievement of the following goals:

- identification of the problem and its consequences;

- definition of strategic, tactical and operational goals aimed at reducing risk;

- building a program to minimize risks;

- monitoring, control and adjustment of the risk management system.

Comprehensive measures aimed at minimizing and eliminating risks can allow the enterprise to independently determine the stages, depending on the goal and available funds. In the enterprise risk management system, it is necessary to rely on the following provisions: - risk management should be carried out within the framework of the general enterprise management system

- the decision to prevent or minimize the risk must be economically justified, made on the basis of extremely reliable data, taking into account the peculiarities of the environment of the enterprise;

- internal documents should be developed that regulate issues in the field of risk management, which outline the principles, methods of risk management, taking into account the specifics of the given enterprise;

- a system of control of the enterprise's business processes should be formed to identify risk situations;

- to control and risk management functions are well present effective feedback, involves making decisions on the basis of the currently second analysis of a current situation and previous decisions.

\section{Conclusion}

The application of the risk management system at the enterprise carries with it positive aspects in the effective regulation of its activities: the implementation of the system increases the business reputation of the enterprise; the relationship with corporate governance is increasing; monitoring and reduction of risks is ensured, which positively affects the growth of economic indicators, strengthens partnerships, increases competitiveness, and the development of innovative processes; a single target orientation of the strategy for the effective development of the organization is formed; there is dynamics in achieving the set goals, transformation of management strategies; conditions are created for consistency and consistency of actions; there is an orientation towards the needs of investors, shareholders and management; there is validity in decision-making, transparency and reliability of data in terms of risk situations and their elimination.

Thus, the need for the formation and development of a risk management system is due to their multifactorial nature, the ability to influence a risk event by changing or creating conditions for the occurrence, development and course, characteristics of the dynamic correction of an already carried out event and the preparation of appropriate conditions for 
responding to risks in the environment of the enterprise's functioning to ensure it. economic security.

\section{References}

1. Decree of the President of the Russian Federation of 13 .05. 2017 No. 208 "On the Strategy of Economic Security of the Russian Federation for the Period up to 2030". https://www.garant.ru/products/ipo/prime/doc/71572608/

2. Concept for the development of the national system for combating the legalization (laundering) of proceeds from crime and the financing of terrorism (approved by the President of the Russian Federation on 05/30/2018) . http://www.consultant.ru/document/cons_doc_LAW_299375/7327668c04c0470317b2 6d354e36cb828a4af319

3. Law of the Russian Federation of 27.11.1992 No. 4015-1 (as amended on 30.12.2020) "On the organization of insurance business in the Russian Federation". https://fzrf.su/zakon/ob-organizacii-strahovogo-dela-n-4015-1/

4. Federal Law of October 29, 1998 No. 164-FZ (as amended on October 16, 2017) "On Financial Lease (Leasing)". - https://fzrf.su/zakon/o-finansovoj-arende-lizinge-164fz/st-21.php

5. Federal Law of December 27,2002 No. 184-FZ (as amended on December 22, 2020)

" On Technical Regulation " (as amended and supplemented, entered into force on January 2021)

http://www.consultant.ru/document/cons_doc_LAW_40241/4ceedc6beeab98acfcffe6b 042e41a8319e1c922/

6. Order of the Federal Tax Service of Russia dated June 16, 2017 No. MMB-7-15 / 509 (a) " On approval of the Requirements for the organization of the internal control system " (Registered in the Ministry of Justice of Russia on 04.10.2017 N 48424) . http://www.consultant.ru/document/cons_doc_LAW_279362/40633464d2f2199a390b ef8ea1661b75c284f7dd/

7. Panfilova E.A. The concept of risk: a variety of approaches and definitions // Theory and practice of social development. 4, 30-34, (2010).

8. Razuvaev V.V. Theoretical definition of the concept of risk // Modern scientific research and innovation. 9, (2016) - http://web.snauka.ru/issues/2016/09/72007

9. Kuvshinkina E.B. Fundamentals of financial risk management in the activities of the organization // ECONOMICS "COLLOQUIUM - JORNAL". 1 (53), 130-132, (2020).

10. Avdiyskiy V.I. Risk management in the activities of the economic entities // Economy. Taxes. Right. 4, 4-12, (2013). 